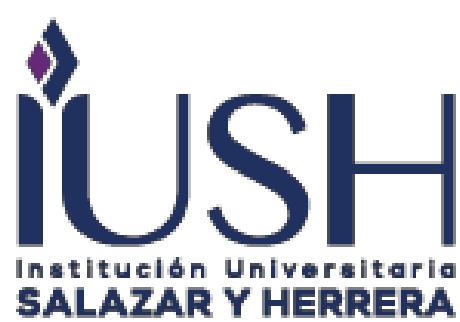

QUID 2017, pp. 1156-1166, Special Issue №1- ISSN: 1692-343X, Medellín-

Colombia

\title{
DESIGNING A FUZZY EXPERT DECISION SUPPORT SYSTEM BASED ON DECREASED RULES TO SPECIFY DEPRESSION
}

(Recibido el 22-05-2017. Aprobado el 16-09-2017)

\author{
Hamed Movaghari \\ MSc student, Department of \\ Computer Engineering, Islamic \\ Azad University Mahmudabad \\ Branch, Mahmudabad, Iran, \\ hmovaghari@iaumah.ac.ir
}

\author{
Rouhollah Maghsoudi \\ Instructor, Department of \\ Computer Engineering, Islamic \\ Azad University Mahmudabad \\ Branch, Mahmudabad, Iran \\ r.maghsoudy@srbiau.ac.ir
}

\author{
Abolfazl Mohammadi \\ Assistant professor, Hospital \\ Rouzbeh, Tehran medical \\ sciences university, Tehran, Iran, \\ a-mohammadi@tums.ac.ir
}

Resumen. La depresión es un trastorno psicológico, si no se diagnostica y cura en el tiempo, puede afectar la calidad de la vida de los humanos en amplias dimensiones. Por lo tanto, el diagnóstico fácil y rápido es la necesidad necesaria de la socialidad en general saludable. El objetivo de este trabajo es diseñar un sistema de apoyo a la toma de decisiones de ANFIS para implementar BDI-II. Las preguntas para BDI-II se agrupan en múltiples factores. En las ciencias médicas, trastornos y enfermedades que carecen de alta confianza y complejidad en el diagnóstico, los sistemas inteligentes tienen una mayor capacidad de confianza en el diagnóstico. En esta inversión, la estructura está diseñada en forma de dos factores y cinco factores. Los resultados muestran que el sistema diseñado con dos factores en comparación con cinco factores de estructura con $94,2 \%$ de potencia de diagnóstico tiene implementaciones de datos de tren de BDI-II. Por lo tanto, en el futuro, el psicólogo puede utilizar este sistema como un sistema de apoyo a la decisión de apoyo a la decisión en los diagnósticos clínicos y hospitalarios.

Palabras clave: Lógica difusa, ANFIS, Depresión, BDI-II

\begin{abstract}
Depression is one psychological disorder, if it doesn't be diagnosed and cured in time, can effect on quality of humans' life in wide dimensions. Thus, diagnosis easily and quickly is necessary need of sociality's generally healthy. The aim of this paper is designing an ANFIS decision support system to implement BDIII. Questions for BDI-II is grouped into multiple factors. In medical sciences, disorders, and diseases that lack high confidence and complexity in diagnosis, intelligent systems have better confidence capacity in diagnosis. In this investment, the structure is designed in form of two factors and five factors. The results show that designed system with two factors compared to five factors structure with $94.2 \%$ diagnostic power has implementations train data of BDI-II. Hence, in future, the psychologist can use this system as a decision support system of decision support in clinical and hospital diagnoses.
\end{abstract}

Keywords: Fuzzy Logic, ANFIS, Depression, BDI-II 


\section{INTRODUCTION}

Depression as one of the common psychiatry diseases is a major threat to the general healt (Yach, Stuckler \& Brownell, 2006). This thread with vanity sense and physical and cognitive changes has the effect on one's performance ability (DSM-5, 2013). Bad sense and disappointment continue until the person cannot act at all (Organik \& Tarigan, 2003). And it reduces the quality of social, interpersonal, occupational or educational performance (Nussbaum, 2013). Providing guides that can affect while helping to clinic judgment in diagnosis and diagnostic information, and as established diagnostic system upgrade value and decision reliability, is a psychiatry need (DSM-5, 2013). Reliable diagnosis is a basic need in curing mental disorders, based on which, many manuals are offered in responsibility such as $\mathrm{DSM}^{1}, \mathrm{BDI}^{2}$ (Fried, Epskamp, Nesse, Tuerlinckx \& Borsboom, 2016). According to concepts of fuzzy sets and fuzzy logic in numerous articles and related questions: if disease in BDI-II ${ }^{3}$ has scored such as 46 between interval 29 to 63 that is in severe depression range. But does this person belong to this set? This set represents that all diagnoses and symptoms in emotional-cognitive and physical axes influenced by disease. But the person has score 46, in fact, is semi-depressed and severe semi-depressed. In other words, if we suppose severe depression as black and depression as white, that person's depression with score 46 has the spectrum of gray. In fact, there is no boundary between a patient and health (Kosko, 1993) (Wang \& Gorenstein, 2013). Therefore, we need a hypothesis that can formulate human science systematically and put it with other mathematical models in engineering systems. In medical sciences also ambiguity and uncertainty are effects. This problem is obvious and related to medical nature. Because diseases appear as various forms and with various severities. In fact, the best definitions of symptoms and illnesses are presented using vague and inaccurate language terms (Torres \& Nieto, 2006). Wang (1999) writes, fuzzy systems model vague phenomena and basically, the fuzzy theory that defined by Professor Zadeh is an accurate theory. There are two types of justification for fuzzy theory: first, due to the complexity of the real world, one cannot offer exact description. Hence, fuzzy has introduced that has the power of analysis. Second, due to the importance of human science and

\footnotetext{
${ }^{1}$ Diagnostic and statistical manual of mental disorders

${ }^{2}$ Beck Depression Inventory

${ }^{3}$ Beck Depression Inventory Second Version

${ }^{4}$ Fuzzy C-means
}

knowledge, we need a hypothesis that can be formulated systematically (Wang, 1999).

In this relation, $\mathrm{Yu}$, and $\mathrm{Yu}$ (2007), to determine the validity and reliability of scores of BDI-II in determining the severity of depression, through a fuzzy logic model of the Chinese version were used. The method has been fuzzy logic. Samples of this study, 204 (123 women and 81 men). The results showed that the reliability of the Chinese version of the BDI is higher than the original version. The analysis also showed that Both versions have the ability to recognize of the clinical and nonclinical (Chinese version $80.3 \%$ and original version $73.2 \%$ ). Finally propose, Due to the better diagnostic power of the Chinese version, Besides its use in medical diagnosis used in engineering research.

$\mathrm{Yu}$ and Lin (2008), applied a score of BDI-II by clustering technic $\mathrm{FCM}^{4}$ and compared it with clustering technic k-means. All of the samples in this study 559 (240 clinical, 319 nonclinical) respectively. The results showed that clustering FCM has less cognitive cost in healthy observances.

Ariyanti et al (2010), divided 21 questions of BDI-II with five factors structure and implemented it with Sugeno fuzzy inference system. The results showed that designed system has high value in psychiatry diagnosis.

Chatvpadhyay et al (2011), due to the ambiguity of depression (mild, moderate and severe) for physicians, $\mathrm{BPNN}^{5}$ offered an appropriate way to determine the exact scores.124 samples were selected to answer 26 questions. $70 \%$ data for train and $30 \%$ were used in the test. The results showed that The propagation neural network $(100 \%$ mild depression, $77 \%$ moderate and $90 \%$ severe depression) to detect. Finally, a suitable model was implemented with $\mathrm{R}=94 \%$ (Chattopadhyay, Kaur, Rabhi \& Acharya, 2011)

Zhang et al (2011), according to the association between depression and heart rate variability. Data of 10 depressed patients and 10 healthy controls heart rate variability were collected. Changes in heart rate with her $\mathrm{ECG}^{6}$ was recorded for a period of 800 seconds. 6 features heart rate changes were extracted. A cluster-based neurofuzzy system with fuzzy membership function was implemented. The results showed that there is

\footnotetext{
${ }^{5}$ Back propagation neural network

${ }^{6}$ Electro Cardio Graphy
} 
a clear difference between heart rate and depression. Therefore, this method can be used in mobile phone applications. As a regulatory system in an emergency to help people.

Chatvpadhyay et al (2012), for the screening and diagnosis of telling states of depression (mild, moderate and severe), two supervised learning algorithms (classification with BPNN and ANFIS $^{7}$ classifiers) and unsupervised (clustering technique with $\mathrm{SOM}^{8}$ ) used both methods was given. And the performance of the two methods was compared. The results showed that a hybrid system is ANFIS compared with BPNN classifier has better performance and help diagnose depression.

Ekong et al (2012), used BDI-II with five factors structure with effective parameters on depression such as age, systolic hypertension, diastolic, and body mass index in the investigation, simulated a fuzzy system through the neuro-fuzzy system and ANFIS inference system. The results showed that using BDI-II with physiological parameters effective on making depression by using expert intelligent system is an effective factor in depression diagnosis. Hence, they suggested that due to being effectiveness above way, we develop this method in heart, pulmonary and cancer diseases.

Chattopadhyay (2013), to model the process of diagnosing depression of the two Fuzzy Clustering Techniques (FCM and $\mathrm{FkNN}^{9}$ ) used. The study sample was 302 people. Information was collected through questionnaires in India. Data analysis was performed using Cronbach's alpha test. Results showed that both are correct diagnostic power with the reliability of 0.98 . nevertheless proposed $\mathrm{GA}^{10}$ to optimize the purpose of this study was to.

Misra et al (2013), due to differences of opinion physicians in determining the severity of depression, expressed a combination of expert tools. The instrument used a combination of (1) information confirmed by experts and specialized resources of the signs and symptoms of depression (2) multilayer feedforward backpropagation neural network). The samples were 302 adults. Each of the samples 16 symptoms of depression, such as sadness, pessimism and... respectively. Signs and symptoms were used as input. $70 \%$ data for train and $30 \%$ were used for testing. Results showed that Tools proposed have a $98.96 \%$ average

\footnotetext{
${ }^{7}$ Adaptive network-based fuzzy inference system OR

Adaptive neuro-fuzzy inference system

${ }^{8}$ Self-organizing map

${ }^{9}$ Fuzzy k-Nearest Neighbour
}

diagnosis. And with all signs and symptoms of accuracy is $98.91 \%$.

Ekong et al (2013), a fuzzy logic expert system to determine the risk levels of depression in consultation with psychiatrists and psychologists from the group consisting of two hospitals Nigeria, were implemented. The consultation, in order to select three physical symptoms (age, blood pressure, and body mass index) and a predictor of psychological symptoms $\left(\mathrm{GHQ}^{11}\right)$, respectively. 125 depressed adults were enrolled. Results showed that the system implemented has the power to detect the risk of depression is the same with experts psychiatry and psychology expert.

Chattopadhyay (2014), offers a mathematical model to understand symptoms and depression diagnosis by using clinical psychiatrists. This model is revised completely with DSM-IV-TR ${ }^{12}$. In this model, with the help of clinical psychiatrists, 14 symptoms of adult depression are considered by the American Society of Psychiatrists in the last resort. Each of these symptoms is measured according to power and pathogenicity severity by expert psychiatrists. Then, by using principal component analysis, 7 Factors are derived from 14 Factors. Then by using these 7 Factors as the input of a controlling system, Then, using these 7 factors as the input of a fuzzy Mamdani composite controller system in the multi-layered back propagation of the neural network was used. The output of this controlling system is regulated by algorithm after publishing neural networks. Finally, by using 302 adult depressed patients and 50 healthy persons, it is $r$ concluded that hybrid controller system can diagnose depression in adults with $95.50 \%$ accuracy.

Mukherjee et al (2014), two types of intelligent neural network (Propagation neural network and neural network with radial basis function) to simulate the data examined depression. This research during 2004 to 2005 with a total of 300 samples (which were first referred to the hospital and did not consume any antidepressant medication and had suicidal thoughts), was selected by 3 expert psychiatrists (average experience of 10.4 years). The results showed that both intelligent neural network considerably very low error, and both instruments are the right techniques in automatic detection of depression. But the neural network with radial basis function compared with propagation neural network is

\footnotetext{
${ }^{10}$ Genetic Algorithm

${ }^{11}$ General Health Questionnaire

${ }^{12}$ DSM IV Text Revise
} 
better. Finally propose to reach a final diagnosis of depression, increased number of test samples.

Chatvpadhyay (2014), To mechanize the process of diagnosing depression Psychiatric Association's DSM-IV-TR America, with Purposive sampling 270 samples from each of the samples East Indian hospital has seven clinical depression factors were collected over two years. Then five expert psychiatrists and psychologists in consultation with the validity and reliability (statistically) examined data collected. This data was simulated by a fuzzy neural model. The neuro-fuzzy system, the functions of the Gaussian triangular membership and membership functions in two modes were considered mild depression and moderate depression. The results show a neuro-fuzzy system with Gaussian membership functions, the best model for automating the accurate prediction of depression was $94.4 \%$.

Mohammadzadeh et al (2016), by using EEG data evaluated by experts and choosing 65 patients by convenient sampling and applying it with two algorithms of educations after publishing artificial neural and neuro-fuzzy network concluded that neuro-fuzzy algorithm is suitable for depression diagnosis with $76.88 \%$ accuracy.

This study has checked designing fuzzy decision support system based on decreased data with rules to diagnosing depression severity. To design this system, first, we produce data set of inputs and output related to BDI-II by expert and uses it to design an ANFIS decreased with rules in five factors and two factors structure.

\section{BDI-II}

BDI-II has 21 self-reported multi choices to measure depression severity in adults and adolescences with age 13 and more. To use this inventory, we must answer 21 questions, then, relate a number from 0 to 3 to each choice. Sum of numbers related to selected choices equals depression severity that psychiatrists refer it as depression score. This score in number between 0 to 63 , by which we can determine depression in four sets. These four sets are determined as:

1) 0 to 13 , healthy or minimal depression

2) 14 to 19 mild depression

3) 20 to 28 moderate depression

4) 29 to 63 serve depression (Ariyanti, Kusumadewi \& Paputungan, 2010) (Beck, Steer, Brown, 1996)

These sets can be shown as the diagram in Figure 1 .

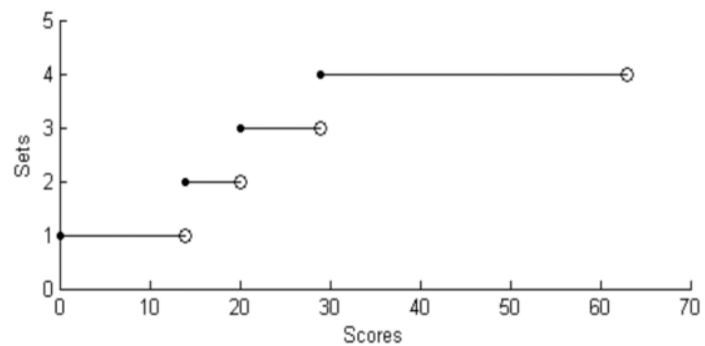

Figure1. diagram of depression severity in BDI-II

According to psychological expert persons, we can divide 21 questions of BDI-II in various structures (Wang, Gorenstein, 2013). In this investigation, two five factors and two factors structures are checked. five factors structures of 21 questions are grouped into five Factors: emotional, cognitive, motivational, physical, and delusional, as are shown in the Table (1) (Ariyanti, Kusumadewi \& Paputungan, 2010) (Wang \& Gorenstein, 2013)

\begin{tabular}{|l|l|}
\hline \multirow{4}{*}{ Factors } & Test \\
\hline \multirow{5}{*}{ Cognotional } & Sadness \\
\cline { 2 - 2 } & Crying spells \\
\cline { 2 - 2 } & Agitation \\
\cline { 2 - 2 } & Loss of Interest \\
\cline { 2 - 2 } & Irritability \\
\hline \multirow{5}{*}{} & Pessimism \\
\cline { 2 - 2 } & Sense of Past Failure \\
\cline { 2 - 2 } & Guilt \\
\cline { 2 - 2 } & Punishment feelings \\
\cline { 2 - 2 } & Self-Dislikes \\
\cline { 2 - 2 } & Self-Criticalness \\
\cline { 2 - 2 } & Indecisiveness \\
\cline { 2 - 2 } & Worthlessness \\
\cline { 2 - 2 } & Concentration Difficulty \\
\hline Motivational & Change in sleep pattern \\
\cline { 2 - 2 } & Changes in Appetite \\
\cline { 2 - 3 } & Fatigue \\
\cline { 2 - 2 } & Loss of interest in sex \\
\hline Physical & Loss of Pleasure \\
\cline { 2 - 2 } & Loss of Energy \\
\hline Delusional & Suicidal Thoughts \\
\hline
\end{tabular}

Table 1. BDI-II with five factors structure

The structure of the two factors of 21 questions is grouped into two cognitive-affective and somatic Factors and is shown in the Table 2 (Wang \& Gorenstein, 2013). (Storch, Roberti \& Roth, 2004)

\section{Factors Test}

Cognitive- Sadness

\begin{tabular}{l|l} 
affective & Crying spells
\end{tabular} 


\begin{tabular}{|c|c|}
\hline & Sense of Past Failure \\
\hline & Guilt \\
\hline & Punishment feelings \\
\hline & Self-Dislikes \\
\hline & Self-Criticalness \\
\hline & Pessimism \\
\hline & Loss of Pleasure \\
\hline & Loss of Interest \\
\hline & Worthlessness \\
\hline & Suicidal Thoughts \\
\hline & Indecisiveness \\
\hline & Irritability \\
\hline & Agitation \\
\hline & Loss of interest in sex \\
\hline \multirow[t]{5}{*}{ Somatic } & Fatigue \\
\hline & Loss of Energy \\
\hline & Concentration Difficulty \\
\hline & Changes in Appetite \\
\hline & Change in sleep pattern \\
\hline
\end{tabular}

Table 2. BDI-II with 2 factor structure

\section{FUZZY LOGIC}

Fuzzy in glossary means vague, inexact, unknown, ambiguous, dizzy and chaotic (Oxford dictionary of English: Oxford University, 2010). First, following setting up fuzzy sets has introduced by Professor Zadeh (1965). Fuzzy sets were founding a successful method to modeling uncertainty and ambiguous (John \& Coupland, 2007). Kosko in fuzzy thinking writes, there has been a wrong in science that all scientists have committed. According to classic logic (Aristotelian, two values and boolean), everything proved by a constant principle, that thing is correct or false. The mistake of science is the generalization of this issue to all phenomena (Kosko, 1993). Any kind of Fact Expression is not entirely correct or false. Their truth is that between complete and complete incorrectness (Torres \& Nieto, 2006). In other words, the expression of reality is not correct or incorrect. The fact of them is something between correctness and incorrectness. This is, something between one and zero if we suppose correctness as white and incorrectness as black. Fuzzy logic is something between black and white, gray (Kosko, 1993). Fuzzy logic is a form of logic that is used in some expert systems and artificial intelligence programs, and in which, variables can show degrees of "correctness" or "incorrectness" by the wide range between 1 (correct) and 0 (incorrect) (Aiken, 2002). One of the fuzzy logic advantages is this that one can refrain complex calculations by using linguistic variables, and also these variables make better understanding ( $\mathrm{Yu}$, Wang \& Chen, 2006). Professor Zadeh, first, offered the concept of calculation in 1996 that based on this, fuzzy logic almost equals with words calculations (Zadeh, 1996; 1999). The structure of fuzzy systems is defined in two types Mamdani and Sugeno. If the conditional rules of the fuzzy system in Sections Antecedent and Consequent are expressed in terms of fuzzy sentences and variables, this system is defined in Mamdani kind. And if the conditional rules of the system phase in Section antecedent are expressed as sentences and fuzzy variables, and in Section Consequent, it is expressed as a function of inputs or a fixed function, a fuzzy system is defined in Sugeno kind. In the fuzzy Sugeno systems, of the section Consequent of the function is constant, the degree is zero, and if section Consequent is defined as a function of degree $n$, it is called the degree $n$ (Jang, 1993). To implement a fuzzy system, we must have input and output linguistic variables and expert person's knowledge. If in the description at least one of these cases, there is no enough knowledge or interference, we must use metaheuristic algorithms and soft computing and methods such as Lookup Tables, clustering, $\mathrm{GD}^{13}$ learning, RLS ${ }^{14}$, ANFIS and design fuzzy system from input-output data (Wang, 1999) (Abraham, 2005). In another hand, some time may our peripheral problems become do wide and complicated that increases number of rules. Choosing rules is important, because increasing number of rules may reach cardinal numbers that will complicate the system and decrease speed in intelligent programs (Wang, 1999) (Abraham, 2005). For example, in BDI-II, we have 21 multichoice questions. If we design this problem without using a certain tool and only by using fuzzy logic, the number of rules in this issue will be computed by relation (1).

$$
\mathrm{m}^{\mathrm{n}}
$$

In relation (1), $\mathrm{m}$ represents the number of conditions of any input (number of choices of any question) and $\mathrm{n}$ is a number of inputs (number of questions) (Ledeneva, García \& Méndez 2007). And by replacing and computing, we reach the amount of 4398046511104 of the rule. If we divide 21 questions of BDI-II by five factors and two factors structures, the number of above rules in five factors and two factors structure decreased as 1024 and 16, respectively. In such issues, we also can use clustering technic to decrease the number of rules. So a number of rules equal with the number of clusters (Wang, 1999). 


\section{ANFIS}

ANFIS, architecture to implement non-linear issues with the framework of the system is educable and adaptable that is hybrid of the fuzzy inference system and artificial neuro-fuzzy networks in designing intelligent systems (Jang, 1993) (Abraham, 2005). In this method, by using learning algorithms and data sets, parameters related to a Sugeno fuzzy inference system such as membership functions and rules are produced (Jang, 1991) (Maghsoudi \& Moshiri, 2016). fuzzy inference system and artificial neural networks are supplementary. Because when there are no enough samples to test or direct method to extract rules or have interference, we can use artificial neural networks (Abraham, 2005). Indeed, ANFIS is a logical system called as fuzzy logic to compute hidden uncertainty in data exactly. This work is done by fuzzification input through membership functions that depict diagram-like relation between input amount and interval $(1,0)$. One can gain these components in input such as membership functions through algorithms such as post-publication or least squares. Then, unlike multilayer perceptron in which weights are updated, in ANFIS, fuzzy linguistic rules or ifthen conditional rules orders are determined for the learning process. Figure 2 shows the general structure of an ANFIS. The main problem in ANFIS to modeling is selecting a fuzzy inference system. In this part, the fuzzy inference system is a linear equation and one can compute its parameters by using a simple method of least squares (Maghsoudi \& Moshiri, 2016).

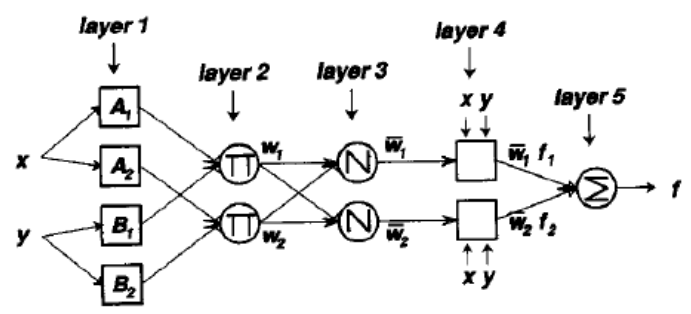

Figure 2. Structure equals with ANFIS (Jang, 1993).

For example, suppose we have a fuzzy inference system with two inputs $\mathrm{x}, \mathrm{y}$ and output $\mathrm{y}$. one can use ordinary rules according to relation (2) and (3) with if-then conditional rules to define a fuzzy model of first order Sugeno.

Rule(1): if $x$ is $A_{1}$ and $y$ is $b_{1}$ Then $f_{1}=p_{1} x+q_{1} y+r_{1}$ Rule(1): if $x$ is $A_{2}$ and $y$ is $b_{2}$ Then $f_{2}=p_{2} x+q_{2} y+r_{2}$

Where $A_{1}, A_{2}, B_{1}, B_{2}$ are membership functions of fuzzy sets that are considered as input for $\mathrm{x}$ and $\mathrm{y}$. in other words, very $\mu_{A i}(\mathrm{x})$ and $\mu_{B i}(\mathrm{x})$. Term of
$\mu_{A i}(\mathrm{x})$ is degree of input membership $\mathrm{x}$ in $\mathrm{A}_{\mathrm{i}}$ set. There are membership functions that can be divided to groups such as Gaussian shape, Triangle, Trapezoid and general bell.

In fact, $A_{i}$ and $B_{i}$ convert crisp values to fuzzy kind. Parameters $r_{1}, r_{2}, p_{1}, p_{2}, q_{1}$ are related to output function parameters. ANFIS architecture such as that shown in Figure (2). All nodes of layers related to ANFIS perform equally. ANFIS performance follows as:

Layer 1: each of nodes of this layer creates membership degree of one of the input components; this is, determines fuzzy parts of input space.

$$
\begin{aligned}
& o p_{i}^{1}=\mu_{A_{i}}(x) \text { for } i=1,2 \text { or } \\
& o p_{i}^{1}=\mu_{B_{i}}(y) \text { for } i=3,4
\end{aligned}
$$

In relation (4), $\mathrm{x}$ or $\mathrm{y}$ are inputs of any node. $\mathrm{A}_{\mathrm{i}}$ or $\mathrm{B}_{\mathrm{i}-2}$ is fuzzy set that interacts with this node and defines as membership functions. Such as functions can be any kind of proper, continued fragment, a derivable function such as Gaussian, general bell, Triangle, and Trapezoid.

Layer 2: nodes send input signals of this layer to each other. This process is shown as $\pi$.

$o p_{i}^{1} \quad$ That is basic motivate force, forms as relation $(5)$ :

$$
o p_{i}^{2}=w_{i}=\mu_{A_{i}}(x) \cdot \mu_{B_{i}}(y), i=1,2
$$

In other words, this layer is a place of applying operators T-norms, such as product or minimum.

Layer 3: with $\mathrm{I}^{\mathrm{s}}$ in this layer (is shown as $\mathrm{N}$ ), normalizing input signals is done:

$$
o p_{i}^{3}=\bar{w}=\frac{w_{i}}{w_{1}+w_{2}}, i=1,2
$$

Layer 4: with node $\mathrm{I}^{\mathrm{s}}$, in this layer, the participation rate of any rules is computed in output:

$$
o p_{i}^{4}=\bar{w} f_{i}=\bar{w}\left(p_{i} x+q_{i}+r_{i}\right)
$$

Layer 5: this layer computes final ANFIS layer (Maghsoudi \& Moshiri, 2016):

$$
o p_{i}^{5}=\sum_{i} \bar{w} f_{i}=\frac{\sum_{i} w_{i} f_{i}}{\sum_{i} w_{i}}
$$

To product, primarily Sugeno fuzzy system, one can use grid partition, subtractive clustering, and 
clustering FCM methods. Since grid partition method in this issue, while doesn't decrease the number of rules, increases the number of output membership functions, and the number of rules. Therefore, one can use subtractive clustering and FCM. In this article, we use subtractive clustering. Based on this, the number of rules equals with a number of determined clusters (Wang, 1999). In this paper, a hybrid learning algorithm is used to train the fuzzy inference network. This algorithm first has introduced by Jang in 1997. In this kind of algorithm, to find optimum parameters of the Sugeno fuzzy inference system, we use gradient descent method and least squares estimate. One of the basic advantages of this algorithm is its speed that is used more in online work (Jang, 1993).

\section{PURPOSE METHOD}

To implement BDI-II by software MATLAB and ANFIS, we need to a data set. This data set included the knowledge of expert psychiatry and psychology (10 Person) and confirming and reliability by them.

\section{IMPLEMENTATION AND EXPERIMENTAL RESULTS}

After receiving data set related to five factors and two factors structure, first divided to $70 \%$ train data, $15 \%$ validation data and $15 \%$ test data. Then cluster train data with subtractive clustering that because the number of output sets of BDI-II has four sets, the number of four clusters devoted to them. Allocating 4 clusters by regulating radial of clustering for train data related to five factors and two factors structure are regulated equally to 0.9222 and 0.7212 respectively. After clustering, two Sugeno fuzzy inference system is produced. Because of using subtractive clustering, the number of rules becomes equal to a number of determined Sugeno fuzzy inference system, thus, the number of rules for five factors structure decreased from 1024 to 4 and for two factors structure from 16 to 4 . Amounts of parameters of these two Sugeno fuzzy inference system are shown in the Table 3.

\begin{tabular}{|l|l|}
\hline Amount & Parameter \\
\hline Prod & And \\
\hline Probor & Or \\
\hline Prod & Implication \\
\hline Max & Aggregation \\
\hline Wtaver & Defuzzification \\
\hline
\end{tabular}

\begin{tabular}{|l|l|}
\hline Gaussmf & $\begin{array}{l}\text { Input Membership } \\
\text { Function }\end{array}$ \\
\hline Linear & $\begin{array}{l}\text { Output Membership } \\
\text { Function }\end{array}$ \\
\hline
\end{tabular}

Table 3. parameters of Sugeno fuzzy inference system

The structure of ANFIS for five factors (right) and two factors (left) is shown in Figure 3.

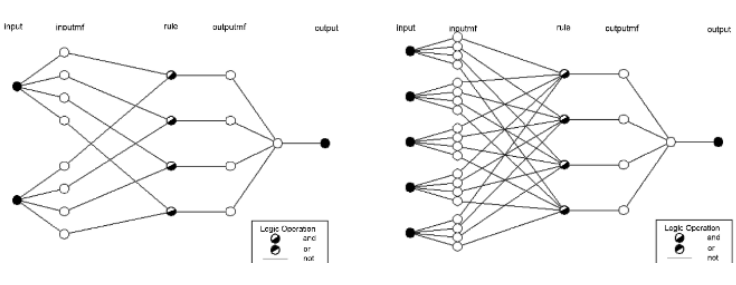

Figure 3. Five factors and two factors structure of ANFIS

Two Sugeno fuzzy inference systems of two factors and five factors structure are trained by using ANFIS and hybrid learning algorithm. Amounts of parameters related to training these two Sugeno fuzzy inference systems are shown in the Table 4.

\begin{tabular}{|l|l|}
\hline Parameter & Amount \\
\hline epoch & 1000 \\
\hline Error tolerance & 0 \\
\hline Initial step size & 0.001 \\
\hline $\begin{array}{l}\text { Step size } \\
\text { decrease }\end{array}$ & 0.9 \\
\hline $\begin{array}{l}\text { Step size } \\
\text { increase }\end{array}$ & 1.1 \\
\hline
\end{tabular}

Table 4. Parameters of train

Diagram of decreasing error related to train five factors (right) and two factors (left) structure has been shown in Figure 4.
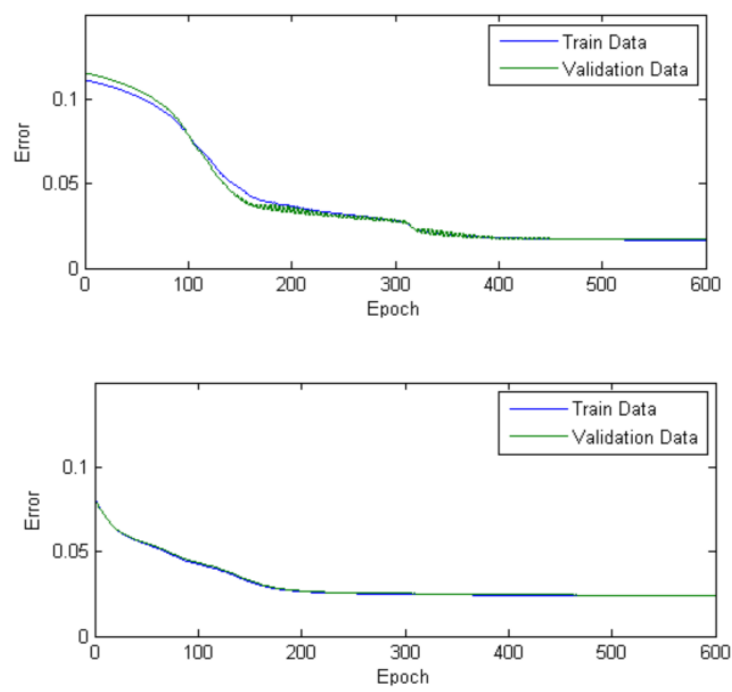
Figure 4. Diagram of decreasing error in train and validation data

The final amount of decreasing error in this train with four decimal digits, for five factors structure, is 0.0238 for train data, 0.0241 for validation data and for two factors structure is 0.0166 for train data, 0.0169 for validation data. These amounts show that two factors structure has better ability than five factors structure in implement train data related to BDI-II.

\section{RELIABILITY AND VALIDITY}

Firstly, parameters and diagram of test data error calculated by MATLAB are shown. Then, using software SPSS was used to calculate the Pearson correlation coefficient and diagnostic power.

Error parameters of the test data for two factors and five factors structure in Table 5 shown.

\begin{tabular}{|l|l|l|}
\hline Parameter & $\begin{array}{l}\text { five } \\
\text { factors }\end{array}$ & $\begin{array}{l}\text { two } \\
\text { factors }\end{array}$ \\
\hline $\begin{array}{l}\text { STD } \\
\text { Error }\end{array}$ & 0.0233 & $\mathbf{0 . 0 1 6 9}$ \\
\hline MSE $^{16}$ & $\begin{array}{l}5.4470 \mathrm{e}- \\
04\end{array}$ & $\begin{array}{l}\mathbf{2 . 8 5 1 8 e} \\
\mathbf{0 4}\end{array}$ \\
\hline $\mathrm{RMSE}^{17}$ & 0.0233 & $\mathbf{0 . 0 1 6 9}$ \\
\hline
\end{tabular}

Table 5. Comparing error of two designed systems related to test data, with five factors and two factors structure

Also, a diagram of error deviation, error histogram, and error regression related to two designed systems related to test data, for five factors structure (right) and two factors structure are shown (left) in Figure 5 to figure 7 respectively.
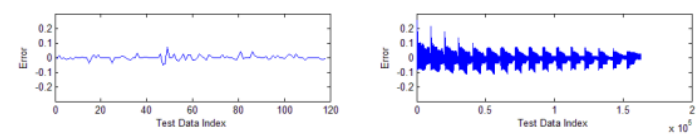

Figure 5. diagram of error deviation related to test data for five factors structure and two factors structure
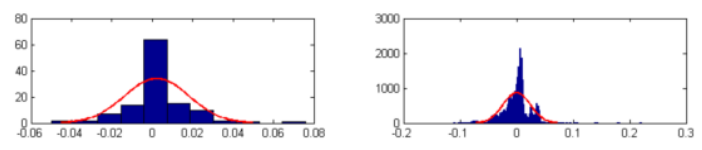

${ }^{15}$ Standard Deviation Error

${ }^{16}$ Mean Squared Error
Figure 6. diagram of error histogram related to test data for five factors structure and two factors structure
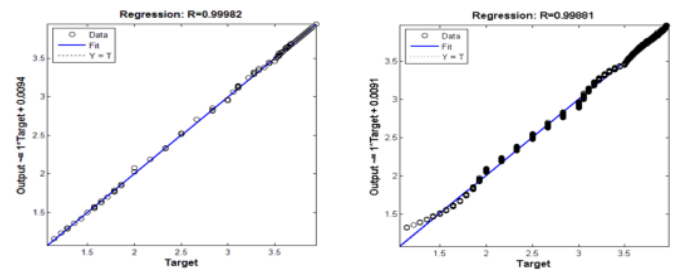

Figure 7. diagram of error regression related to test data for five factors structure and two factors structure

The Pearson correlation coefficient table for five factors and two factors structure by the SPSS software is presented in Table 6 .

\begin{tabular}{|l|l|l|}
\hline & $\begin{array}{l}\text { five } \\
\text { factors }\end{array}$ & $\begin{array}{l}\text { two } \\
\text { factors }\end{array}$ \\
\hline $\begin{array}{l}\text { Pearson } \\
\text { coefficient }\end{array}$ & $0.978^{* *}$ & $\mathbf{1 . 0 0 0}^{* *}$ \\
\hline Sig. (2-tailed) & 0.000 & $\mathbf{0 . 0 0 0}$ \\
\hline
\end{tabular}

According to Table (6), two factors have more complete correlation than five factors. To calculate Diagnostic power, used from Cross tabulation in SPSS software. Diagnostic power for five factors in Table 7 and for two factors in Table 8 shown.

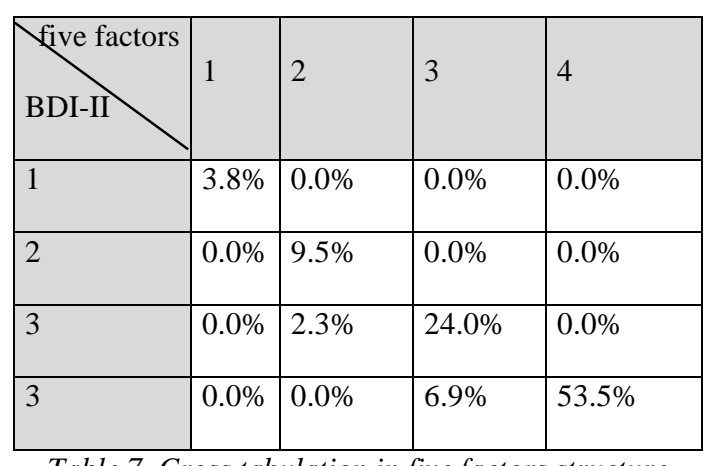

Table 7. Cross tabulation in five factors structure

\footnotetext{
${ }^{17}$ Root Mean Square error
} 


\begin{tabular}{|c|c|c|c|c|}
\hline wo factors & 1 & 2 & 3 & 4 \\
\hline 1 & $13.4 \%$ & $0.0 \%$ & $0.0 \%$ & $0.0 \%$ \\
\hline 2 & $0.0 \%$ & $12.1 \%$ & $0.0 \%$ & $0.0 \%$ \\
\hline 3 & $0.0 \%$ & $2.0 \%$ & $16.3 \%$ & $0.0 \%$ \\
\hline 3 & $0.0 \%$ & $0.0 \%$ & $3.7 \%$ & $52.4 \%$ \\
\hline
\end{tabular}

Table 8. Cross tabulation in two factors structure

The result of Table 7 and 8 shown that by the sum of the elements of the main diagonal of the Cross tabulation can calculate the Diagnostic power. Diagnostic power of the five factors is equal to $90.8 \%$ and for two factors is equal to $94.2 \%$. Which indicates the higher Diagnostic power of two factors.

\section{DISCUSSION}

The results of this investigation according to Tables 5 to 8, and Figures 4 to 7 represent that two factors structure, having advantages such as Diagnostic power 94.2\%, Pearson coefficient 1 with Correlation significant at the 0.01 level and correlation coefficients R in Regression 0.97724 has implemented BDI-II better than two factors structure. Therefore, designing an expert decision support ANFIS with subtractive clustering and hybrid algorithm for BDI-II with two factors structure works better than five factors structure. $\mathrm{Yu}$ and $\mathrm{Yu}$ (2007) compared BDI-II and Chinese version by fuzzy logic. The result showed the Chinese version with diagnostic power $80.3 \%$ is better. Yu and Lin (2008) implemented score of BDI-II by clustering FCM technic and compared it with clustering k-means. The results showed that clustering FCM has less recognizing cost in recognizing. Ariyanti et al (2010) by designing and implementing BDI-II with five factors structure by Sugeno fuzzy inference system, showed that the above system has high value in diagnosis. Ekong et al (2012) have used BDI-II with five factors structure with parameters affecting on depression in the research and simulated it through the neuro-fuzzy system and ANFIS. The results showed that using BDI-II with parameters affecting on creating a depression by using expert intelligent system is an effective factor in recognizing depression. In this paper, the results showed that the structure of the two factors had a higher diagnostic power than the five factors. Therefore, it can be concluded that the design of the expert system has been shown to be more effective in determining the severity of depression with ANFIS. In general, it can be admitted that the two factors structure is better able to detect the severity of depression than previous studies.

\section{CONCLUSION AND SUGGESTIONS}

Considering the superiority of the structure of two factors $(94.2 \%)$, versus to five factors $(90.8 \%)$ is suggested. To recognize depression in patients or the impact of factors affecting depression, it is better to group the parameters associated with depression into two factors structures. Also, by designing psychological inventories through related methods in soft computing and artificial intelligence, one can design recognizing the online hospital soon and in all regions, also used in rural and remote parts, where there is no need for access to psychology and psychiatry experts, and Introduce patient to equipment centers after specifying depression intensify.

\section{ACKNOWLEDGEMENT}

We are grateful to all our participants that support us to do the best. These grand persons are:

President, secretaries, and manager of computer engineering group of Islamic Azad University of Mahmoudabad, honorable chairman of hospital Rouzbeh, the sincere cooperation of Sir Dr. Hamid Haghani, Dr. Homayoun Amini and personnel of clinic of hospital Rouzbeh dependent on Tehran medical sciences university.

\section{REFRENCES}

Abraham, A. (2005). Adaptation of fuzzy inference system using neural learning. Fuzzy systems engineering: Springer; 2005. p. 53-83.

Aiken, P. (2002). Microsoft computer dictionary: Microsoft Press; 2002.

Ariyanti, R.D, Kusumadewi, S., Paputungan, I.V., editors. (2010). Beck Depression Inventory Test Assessment Using Fuzzy Inference System. 2010 International Conference on Intelligent Systems, Modelling and Simulation. IEEE.

Beck, A. T, Steer, R. A, Brown, G.K. (1996) Manual for the beck depression inventory-II. San Antonio, TX: Psychological Corporation. 1,82 . 
Chattopadhyay, S. (2013). A neuro-fuzzy approach for the diagnosis of depression. Applied Computing and Informatics. 2014.

Chattopadhyay, S. (2013). Mathematical modelling of doctors' perceptions in the diagnosis of depression: a novel approach. International Journal of Biomedical Engineering and Technology. 11(1):1-17.

Chattopadhyay, S. (2014). Neurofuzzy models to automate the grading of old-age depression. Expert Systems. 31(1):48-55.

Chattopadhyay, S., Kaur, P., Rabhi, F. \& Acharya, R. editors. (2011). An automated system to diagnose the severity of adult depression. Emerging Applications of Information Technology (EAIT), Second International Conference on, IEEE.

Chattopadhyay, S., Kaur, P., Rabhi, F., Acharya, U. R. (2012). Neural network approaches to grade adult depression. Journal of Medical Systems. 36(5):2803-15.

Diagnostic and statistical manual of mental disorders (DSM-5®) (2013). American Psychiatric Pub.

Ekong, V., Ekong, U.O., Uwadiae, E.E., Abasiubong, F., Onibere, E.A. (2013). A fuzzy inference system for predicting depression risk levels. African Journal of Mathematics and Computer Science Research. 6(10):197-204.

Ekong, V.E., Inyang, U.G. \& Onibere,. EA. (2012) Intelligent decision support system for depression diagnosis based on neuro-fuzzyCBR hybrid. Modern Applied Science, 6(7):79.

Fried, E.I., Epskamp, S., Nesse, R.M., Tuerlinckx, F. \& Borsboom, D. (2016). What are'good'depression symptoms? Comparing the centrality of DSM and non-DSM symptoms of depression in a network analysis. Journal of affective disorders. 189, pp. 31420.

Jang, J-S. (1993). ANFIS: adaptive-networkbased fuzzy inference system. IEEE transactions on systems, man, and cybernetics. 1993;23(3):665-85.

Jang, J-SR, (1991). editor Fuzzy Modeling Using Generalized Neural Networks and Kalman Filter Algorithm. AAAI; 1991.
John, R. \& Coupland, S. (2007). Type-2 fuzzy logic: a historical view. IEEE computational intelligence magazine. 2007;2(1):57-62.

Kosko, B. (1993). Fuzzy thinking: The new science of fuzzy logic: Hyperion Books.

Ledeneva Y, Gelbukh A, García CAR, Hernandez RAG, editors. Automatic Determination of Parameters for Rule Base Reduction of Complex Fuzzy Control Systems. 8th Conference on Computing CORE-2007, Mexico City, Mexico; 2007.

Ledeneva, Y. N., García, C.A.R. \& Méndez JAD, editors. (2007). Automatic estimation of parameters for the hierarchical reduction of rules of complex fuzzy controllers. ICINCOICSO; 2007.

Maghsoudi, R. \& Moshiri, B. (2016). Applying Adaptive Network-based fuzzy Inference System to Predict Travel Time in Highways for Intelligent Transportation Systems. Journal of Advances in Computer Research.

Misra, K., Chattopadhyay, S., Kanhar, D. (2013). A hybrid expert tool for the diagnosis of depression. Journal of medical imaging and health informatics, 3(1):42-7.

Mohammadzadeh, B. (2016) Comparing diagnosis of depression in depressed patients by EEG, based on two algorithms: Artificial Nerve Networks and Neuro-Fuzy Networks. International Journal of Epidemiologic Research.

Mukherjee, S., Ashish, K. \& BaranHui, N. (2014). Chattopadhyay S. Modeling depression data: feed forward neural network vs. radial basis function neural network. American Journal of Biomedical Sciences, American J Biomed Sci. 6(3):166-74.

Nussbaum, A. M. (2013). The Pocket Guide to the DSM-5® Diagnostic Exam: American Psychiatric Pub.

Organik D, Tarigan CJ, (2003) Penelitian alb. perbedaan depresi pada pasien dispepsia fungsional dan.

Stevenson, A. (2010). Oxford dictionary of English: Oxford University Press, USA; 2010.

Storch, E.A., Roberti, J.W. \& Roth, D.A. (2004). Factor structure, concurrent validity, and internal consistency of the beck depression inventory-second edition in a sample of 
college students. Depression and anxiety. 19(3):187-9.

Torres, A, Nieto, J. J. (2006). Fuzzy logic in medicine and bioinformatics. BioMed Research International.

Wang, L-X. (1999). A course in fuzzy systems: Prentice-Hall press, USA.

Wang, Y-P \& Gorenstein, C. (2013) Psychometric properties of the Beck Depression InventoryII: a comprehensive review. Revista Brasileira de Psiquiatria. 2013;35(4):416-31.

Wang, Y-P. \& Gorenstein, C. (2013). Assessment of depression in medical patients: a systematic review of the utility of the Beck Depression Inventory-II. Clinics. 68(9),1274-87.

Yach D, Stuckler D, Brownell KD. (2006) Epidemiologic and economic consequences of the global epidemics of obesity and diabetes. Nature medicine. 12(1), 62-6.

Yu, S-C., Lin, Y-H. (2008). Applications of fuzzy theory on health care: an example of depression disorder classification based on FCM. WSEAS Transactions on Information Science and Applications. 5(1).
Yu, S-C., Yu, M-N. (2007). Fuzzy partial credit scaling: A valid approach for scoring the Beck Depression Inventory. Social Behavior and Personality: an international journal, 35(9), 63-72.

Yu, TH-K, Wang, DH-M, Chen, S-J. (2006). A fuzzy logic approach to modeling the underground economy in Taiwan. Physica A: Statistical Mechanics and its Applications. 2006;362(2):471-9.

Zadeh, L. A. (1965). Fuzzy sets. Information and control. 8(3):338-53.

Zadeh, L. A. (1996). Fuzzy logic= computing with words. IEEE transactions on fuzzy systems. 1996;4(2):103-11.

Zadeh, L. A. (1999) Fuzzy logic= computing with words. Computing with Words in Information/Intelligent Systems 1: Springer; 1999. p. 3-23.

Zhang, Z-X., Tian, X-W., Lim, J.S., editors. (2011). New algorithm for the depression diagnosis using HRV: A neuro-fuzzy approach. Bioelectronics and Bioinformatics (ISBB), International Symposium on 2011: IEEE. 